\title{
A rapid pneumococcal serotyping system based on monoclonal antibodies and PCR
}

\author{
J. Yu, ${ }^{1}$ M. da G. S. Carvalho, ${ }^{2}$ B. Beall ${ }^{2}$ and M. H. Nahm ${ }^{1}$
${ }^{1}$ Department of Pathology, University of Alabama at Birmingham, 845 19th Street South, BBRB 614, Birmingham, AL 35294, USA
${ }^{2}$ Division of Bacterial Diseases, Centers for Disease Control and Prevention (CDC), Atlanta, GA 30333, USA

Correspondence

M. H. Nahm

nahm@uab.edu

\begin{abstract}
Streptococcus pneumoniae expresses at least 91 different polysaccharide (PS) capsules and the currently available serotyping methods are tedious to perform. We have been developing a rapid pneumococcal serotyping assay (named the 'multibead assay') based on the capacity of pneumococcal lysates to inhibit the ability of 24 different anti-capsule antibodies to bind to latex beads coated with 24 different PSs (serotypes 1, 3, 4, 5, 6A, 6B, 7F, 9N, 9V, 14, 18C, 19A, 19F, $23 \mathrm{~F}, 2,8,10 \mathrm{~A}, 11 \mathrm{~A}, 12 \mathrm{~F}, 15 \mathrm{~B}, 17 \mathrm{~F}, 20,22 \mathrm{~F}$ and 33F). Because the polyclonal antibodies used for 10 serotypes (2, 8, 10A, 11A, 12F, 15B, 17F, 20, 22F and 33F) had limited serotype specificity, we replaced them with monoclonal antibodies for the 10 serotypes. To extend the serotype coverage beyond the 24 serotypes, we have adapted multiplexed PCR for five additional serotypes (15A, 15C, 16F, 35B and 38) to be useful with the pneumococcal lysates prepared for the multibead assay. We then validated the combined assay with 157 clinical isolates from the Centers for Disease Control and Prevention and found that the new combined assay produced results that are concordant with the quellung reaction. The combined assay is robust and could be used to rapidly identify the serotypes of the majority of pneumococci ( 90\%). In addition, the assay validation study suggests the presence of serological subtypes within serotype $11 \mathrm{~A}$.
\end{abstract}

Received 1 August 2007

Accepted 30 September 2007

\section{INTRODUCTION}

Because Streptococcus pneumoniae is a significant human pathogen, sustained efforts are under way to improve currently available pneumococcal vaccines (Wuorimaa \& Kayhty, 2002). Since all the currently available pneumococcal vaccines provide protection in a serotype-specific manner, an effective vaccine is predicted to reduce the prevalence of pneumococci expressing the serotypes included in the vaccine without reducing the prevalence of the non-vaccine serotypes (Whitney et al., 2003). Therefore, the efficacy of a vaccine given to a population can be monitored by serotyping pneumococcal isolates from the vaccinated population. Thus an efficient method for serotyping pneumococcal isolates is greatly needed.

Classically, pneumococci are serotyped by the quellung reaction (Henrichsen, 1995; Lund, 1960). Since the quellung reaction is very labour-intensive and requires a complex array of expensive typing sera, new typing systems

Abbreviations: CDC, Centers for Disease Control and Prevention; DMTMM, 4-(4,6-dimethoxy[1,3,5]triazin-2-yl)-4-methyl-morpholinium; EDC, 1-ethyl-3-(3-dimethylaminopropyl)carbodiimide hydrochloride; PLL, poly-L-lysine; PS, polysaccharide; RT, room temperature; UAB, University of Alabama at Birmingham. have recently been developed to meet the large serotyping needs of vaccine studies. Several groups developed DNAbased typing systems following the determination of the DNA sequence of the capsular biosynthetic gene (cps) loci from strains representing 90 pneumococcal serotypes (Batt et al., 2005; Brito et al., 2003; Kong et al., 2005; Lawrence et al., 2003; O'Halloran \& Cafferkey, 2005; Rubin \& Rizvi, 2004). Using extracted DNA, Pai et al. (2006) developed a multiplex PCR for 29 of the pneumococcal serotypes. Other groups developed improved serological assays such as latex agglutination assays (Slotved et al., 2004) and dotblot assays using intact pneumococci (Fenoll et al., 1997). We developed a multiplex immunoassay for capsular polysaccharides (PSs) using pneumococcal lysates and described an assay employing monoclonal antibodies (mAbs) for 14 common serotypes and polyclonal antibodies for 10 additional serotypes (Yu et al., 2005).

Experience with our multiplex immunoassay (named the 'multibead assay') showed that PS-coated latex particles are unstable and polyclonal antibodies have limitations in serotype specificity. To extend the usefulness of our multibead assay, we have covalently coupled PS to latex particles and have now developed mAbs to 10 additional serotypes and have characterized them. Additional serotype 
coverage is important for more detailed coverage, and is potentially of critical importance for serotype surveillance in developing countries. Compared with developing a $\mathrm{mAb}$, developing a PCR for a new serotype is simple. We therefore investigated the new mAbs for the multibead assay method and also investigated combining a PCR method with the multibead method to identify additional serotypes.

\section{METHODS}

Bacterial isolates. To determine the assay specificity, we used 147 pneumococcal isolates kept frozen in our laboratory. The laboratory panel includes 90 isolates purchased from the Staten Serum Institut (Copenhagen, Denmark) representing all 90 known pneumococcal serotypes (Henrichsen, 1995). Also, our laboratory's strain collection includes isolates expressing the 6C serotype, a new serotype that we recently discovered (Park et al., 2007). For clinical validation, a panel of 157 frozen clinical isolates of pneumococci was obtained from the Centers for Disease Control and Prevention (CDC). The CDC isolates were selected to primarily include the serotypes detected by the new mAbs (Tables 1 and 2).

Bacteria were recovered from the frozen isolates by plating scrapings of frozen samples on blood agar plates. After overnight incubation at $37{ }^{\circ} \mathrm{C}$ in a candle jar, microtubes containing $500 \mu \mathrm{l}$ Todd-Hewitt broth with yeast extract $(0.5 \%)$ and $0.001 \%$ bromcresol purple per tube were inoculated with a colony of bacteria. After overnight culture at $37{ }^{\circ} \mathrm{C}$ in a candle jar, $38 \mu \mathrm{l}$ lysing solution $(0.2 \%$ sodium deoxycholate, $0.02 \%$ sodium dodecyl sulfate, $0.1 \%$ sodium azide, $0.3 \mathrm{M}$ sodium citrate; $\mathrm{pH} 7.8$ ) was added to each microtube. The microtubes were then incubated at $37{ }^{\circ} \mathrm{C}$ for about $1 \mathrm{~h}$ to induce lysis of the pneumococci. The resulting bacterial lysates were stored at $-20{ }^{\circ} \mathrm{C}$ until they were analysed.

PCR. To identify capsule genes by PCR, bacterial lysates were diluted 10-100-fold in water and then subjected to PCR using primers and previously described reaction conditions (Pai et al., 2006). The capsule-specific PCR also included primers for part of the cpsA gene, to serve as a positive control for the presence of pneumococcal capsule genes from most pneumococcal strains (Bentley et al., 2006). The reaction products were separated by agarose electrophoresis, stained with ethidium bromide, and visualized under UV light.

Production of mAbs. mAbs were produced as previously described (Yu et al., 2005). Briefly, mice were immunized with a PS conjugated to a protein, and splenocytes were harvested from immune mice for hybridization with fusion partner cells (SP2/0-Ag14). Primary wells containing antibodies to capsular PS were identified using ELISA (Yu et al., 2005). Hybridoma cell lines were established by subcloning the cells in the primary wells twice by limiting dilution. The hybridoma cell lines are listed in Table 1.

Inhibition ELISA for 11A subtypes. While most isolates typed as $11 \mathrm{~A}$ by the quellung reaction were reactive with the Hyp11AM2 mAb, some were not (Table 2). To distinguish between the two subtypes, we named the isolates typed as $11 \mathrm{~A}$ by both methods as $11 \mathrm{~A} \alpha$ and those typed by the quellung reaction alone as $11 \mathrm{~A} \beta$. To investigate this serological phenomenon, we established $11 \mathrm{~A} \alpha$ - or $11 \mathrm{~A} \beta$-specific inhibition ELISAs, as previously described (Park et al., 2007). For the $11 \mathrm{~A} \alpha$ inhibition ELISA, microwells of ELISA plates were coated with $11 \mathrm{~A} \alpha \mathrm{PS}$, which was purchased from the ATCC (Manassas, VA, USA) as 11A PS. To each microwell, variably diluted bacterial lysates and Hyp11AM2 mAb were added. After incubation, unbound $\mathrm{mAb}$ was removed, and bound $\mathrm{mAb}$ was determined using alkaline
Table 1. Twenty-six mAbs used for the multibead assay and their analytical specificities

Specificity is defined in the context of an inhibition-type assay.

\begin{tabular}{|ll|}
\hline mAb & Specificity \\
\hline Old & \\
Hyp6AG1 & $6 \mathrm{~A} / 6 \mathrm{C}$ \\
Hyp19AM1 & $19 \mathrm{~A}$ \\
Hyp19FM3 & $19 \mathrm{~F}$ \\
Hyp3M6 & 3 \\
Hyp5M3 & 5 \\
Hyp1G4 & 1 \\
Hyp6BM1 & $6 \mathrm{~B}$ \\
Hyp7FM1 & $7 \mathrm{~F} / 7 \mathrm{~A}$ \\
Hyp9NM3 & $9 \mathrm{~N}$ \\
Hyp9VG13 & $9 \mathrm{~V}$ \\
Hyp14M11 & 14 \\
Hyp18CM1 & $18 \mathrm{C}$ \\
Hyp4M3 & 4 \\
Hyp23FG3 & $23 \mathrm{~F}$ \\
Hyp6AM3 & $6 \mathrm{~A}$ \\
New & \\
Hyp10AM6 & $10 \mathrm{~A} / 39$ \\
Hyp20G6 & 20 \\
Hyp11AM2 & $11 \mathrm{~A} \alpha / 11 \mathrm{D} / 11 \mathrm{~F}$ \\
Hyp8M2 & 8 \\
Hyp2M1 & 2 \\
Hyp22FM2 & $22 \mathrm{~F} / 22 \mathrm{~A}$ \\
Hyp12FG3 & $12 \mathrm{~F} / 12 \mathrm{~B}$ \\
Hyp15BG5 & $15 \mathrm{~B} /(15 \mathrm{C})$ \\
Hyp17FM6 & $17 \mathrm{~F} / 17 \mathrm{~A}$ \\
Hyp33FG1 & $33 \mathrm{~F} / 33 \mathrm{~A}$ \\
Hyp11AM1 & $11 \mathrm{~A} \beta$ \\
\hline
\end{tabular}

${ }^{*}$ When mAbs do not cross-react fully, the serotype is listed in parentheses.

phosphatase-conjugated anti-mouse immunoglobulin antibody and nitrophenyl phosphate substrate. For the $11 \mathrm{~A} \beta$ inhibition ELISA, another 11A-specific mAb, Hyp11AM1, was used and the ELISA microwells were coated with $11 \mathrm{~A} \beta$ PS, which was prepared as described below.

Purification of 11A $\beta$ PS. $11 \mathrm{~A} \beta$ PS was purified from a 21 culture of pneumococcal strain CDC3455-06, as previously described (Park et al., 2007). Briefly, the PS in the bacterial culture supernatant was precipitated with $70 \%$ ethanol and then purified over an ionexchange column (DEAE-Sepharose) and a molecular mass sizing column (Sephacryl S-300). The fractions containing PS were identified by the anthrone reaction (Ashwell, 1957) and inhibition ELISA for $11 \mathrm{~A} \beta$ PS.

Conjugation of PS to latex beads. Two sets of latex beads conjugated with PS were prepared using PSs purchased from the ATCC, except for the $6 \mathrm{~A}$ and $11 \mathrm{~A} \beta$ PS. 6A PS was obtained from G. Schiffman (Brooklyn, NY, USA) and $11 \mathrm{~A} \beta$ PS was purified as described above. The latex bead sets contained latex beads of different sizes and with different amounts of red fluorescence, which permits one to identify each bead type by flow cytometry. The latex beads 
Table 2. Validation with strains from the CDC

\begin{tabular}{|c|c|c|c|}
\hline \multicolumn{2}{|c|}{ Quellung assay } & \multicolumn{2}{|r|}{ Multibead assay } \\
\hline Serotype & Number & Concordant results & Discordant results and explanations \\
\hline 20 & 12 & 12 & 0 \\
\hline $10 \mathrm{~A}$ & 12 & 12 & 0 \\
\hline $12 \mathrm{~F}$ & 12 & 12 & 0 \\
\hline $15 \mathrm{C}$ & 8 & & \\
\hline $16 \mathrm{~F}^{*}$ & 3 & 3 & 0 \\
\hline $17 \mathrm{~F}$ & 12 & 12 & 0 \\
\hline $22 \mathrm{~F}$ & 12 & 12 & 0 \\
\hline $11 \mathrm{~A}$ & 12 & 9 & Three strains $(3151-06,3455-06,3954-06)$ were NT at UAB with Hyp11AM2 $\dagger$ \\
\hline NT at UAB & 28 & 28 & \\
\hline 4 & 1 & 1 & \\
\hline NT by $\mathrm{CDC} \dagger$ & 1 & 0 & A strain (3069-06) showed a weak signal for serotype 8 \\
\hline Total & 156 & 152 & 4 \\
\hline
\end{tabular}

*Serotyped by multiplex PCR.

$\dagger \mathrm{NT}$, Non-typable. NT at UAB means that the isolate does not express one of the following 37 serotypes: 1, 2, 3, 4, 5, 6A, 6B, 7A/7F, 8, 9L/9N, 9V, $10 \mathrm{~A} / 39,11 \mathrm{~A} / 11 \mathrm{D} / 11 \mathrm{~F}, 12 \mathrm{~B} / 12 \mathrm{~F}, 14,15 \mathrm{~A}, 15 \mathrm{~B} /(15 \mathrm{C}), 16 \mathrm{~F}, 17 \mathrm{~F}, 18 \mathrm{C}, 19 \mathrm{~A}, 19 \mathrm{~F}, 20,22 \mathrm{~A} / 22 \mathrm{~F}, 23 \mathrm{~F}, 33 \mathrm{~A} / 33 \mathrm{~F}, 35 \mathrm{~B}$ and 38 . NT by CDC indicates that the isolates do not express one of the 91 known serotypes.

$¥$ Serotypes included in this category are: three isolates of serotype 13 , one isolate of serotype 29 , three isolates of serotype 31 , three isolates of serotype 34 , three isolates of serotype $7 \mathrm{C}$, two isolates of serotype $18 \mathrm{~A}$, three isolates of serotype $23 \mathrm{~A}$, three isolates of serotype $23 \mathrm{~B}$, one isolate of serotype $28 \mathrm{~A}$, one isolate of serotype $28 \mathrm{~F}$, one isolate of serotype $35 \mathrm{~A}$, one isolate of serotype $35 \mathrm{C}$ and three isolates of serotype $35 \mathrm{~F}$.

included 10 different types of pre-labelled beads, which are available from Bangs Laboratory as the 'QuantumPlex' latex bead set. Others were unstained latex beads with carboxy or amino groups and were also purchased from Bangs Laboratory. In some cases, the unstained beads were stained with 'DiD oil' (an indodicarbocyanine dye from Molecular Probes), as we have previously described (Park et al., 2000).

The PSs were conjugated to the beads using one of the three methods described below. 1-Ethyl-3-(3-dimethylaminopropyl)carbodiimide hydrochloride (EDC) was used to couple PSs of serotypes 6A, 10A, $19 \mathrm{~A}, 19 \mathrm{~F}$ and 20 to the beads with amino groups, as previously described (Zielen et al., 1996). Four hundred microlitres of water containing $1 \%$ bead suspension, $10 \mu \mathrm{g}$ PS $\mathrm{ml}^{-1}$ and $10 \mathrm{mg}$ EDC $\mathrm{ml}^{-1}$ was incubated overnight at $37{ }^{\circ} \mathrm{C}$ with shaking. To the reaction mixture was added $100 \mu \mathrm{l}$ water containing glycine $(250 \mathrm{mM})$ and glucose $(250 \mathrm{mM})$. After $30 \mathrm{~min}$ at room temperature (RT), the beads were washed with PBS containing $0.1 \%$ Tween 20, suspended to $10^{7}$ beads $\mathrm{ml}^{-1}$ in storage buffer (PBS, $0.01 \%$ Tween $20,1 \%$ BSA, $0.02 \%$ azide and $0.1 \%$ glucose), and kept at $4{ }^{\circ} \mathrm{C}$.

The PSs of serotypes 7F and 22F were conjugated using poly-L-lysine (PLL), as previously described (Pickering et al., 2002). These PSs were conjugated to PLL using cyanuric chloride, and the resulting PS-PLL conjugate was purified over a Sephadex G-25 column. The PS-PLL conjugate was then conjugated to latex beads with carboxy groups using a two-step carbodiimide reaction. Carboxylated microspheres $\left(5 \times 10^{7}\right)$ were mixed with $5 \mathrm{mg}$ EDC $\mathrm{ml}^{-1}$ and $5 \mathrm{mg}$ Sulfo-NHS $\mathrm{ml}^{-1}$. After $20 \mathrm{~min}$, the beads were washed and mixed with $500 \mu \mathrm{l}$
PS-PLL. After $1 \mathrm{~h}$ at RT with shaking, the reaction mixture was mixed with $125 \mu \mathrm{l}$ water containing glycine $(250 \mathrm{mM})$ and glucose (250 mM). After $30 \mathrm{~min}$ at RT, the beads were washed with PBS containing $0.1 \%$ Tween 20 , suspended to $10^{7}$ beads $\mathrm{ml}^{-1}$ in the storage buffer, and kept at $4{ }^{\circ} \mathrm{C}$.

The PSs of the remaining serotypes were conjugated using 4-(4,6dimethoxy[1,3,5]triazin-2-yl)-4-methyl-morpholinium (DMTMM), as previously described (Schlottmann et al., 2006). Two and seventenths millilitres of water containing PS $\left(1 \mathrm{mg} \mathrm{ml}^{-1}\right)$ and DMTMM (15 mg ml${ }^{-1}$ ) was kept at RT for $1 \mathrm{~h}$ with shaking. Activated PS was separated from free DMTMM by desalting chromatography, and the fractions containing the activated PS were identified by the anthrone reaction. Two millilitres of activated PS was mixed with $5 \times 10^{7}$ beads with carboxy groups and was incubated overnight at RT with mixing. To the reaction mixture was added $500 \mu \mathrm{l}$ water containing glycine $(250 \mathrm{mM})$ and glucose $(250 \mathrm{mM})$. After $30 \mathrm{~min}$ at RT, the beads were washed with PBS containing $0.1 \%$ Tween 20 , suspended to $10^{7}$ beads $\mathrm{ml}^{-1}$ in the storage buffer, and kept at $4{ }^{\circ} \mathrm{C}$.

Multibead assay. The assay was performed as described previously using the two sets of latex bead mixture (Park et al., 2000; Yu et al., 2005). Set 1 contained beads coated with PSs of serotypes $1,3,4,5$, $6 \mathrm{~A}, 6 \mathrm{~B}, 7 \mathrm{~F}, 9 \mathrm{~N}, 9 \mathrm{~V}, 11 \mathrm{~A} \beta, 14,18 \mathrm{C}, 19 \mathrm{~A}, 19 \mathrm{~F}$ and $23 \mathrm{~F}$. Set 2 contained beads coated with PSs of serotypes 2, 6A, 8, 10A, 11A $\alpha, 12 \mathrm{~F}, 15 \mathrm{~B}, 17 \mathrm{~F}$, $20,22 \mathrm{~F}$ and $33 \mathrm{~F}$. Each set of bead mixture was incubated with a bacterial lysate and an appropriate mixture of mAbs. The bacterial lysate was diluted either 10 -fold or 50 -fold. After incubation, the 
reaction mixture was washed with PBS containing $0.1 \%$ Tween 20 and mixed with fluorescein-conjugated goat anti-mouse immunoglobulin. After $30 \mathrm{~min}$ of incubation, the latex beads were washed and analysed for their fluorescence with a flow cytometer (FACSArray; Becton Dickinson).

\section{RESULTS AND DISCUSSION}

\section{Development of multibead assays for 10 additional serotypes with 11 mAbs}

We have developed mAbs to 10 additional serotypes to replace the polyclonal antibodies that were used for these serotypes in our previous serotyping assays (Lin et al., 2006). Table 1 lists 11 new mAbs, including the two mAbs for the 11A serotype (bottom half), in addition to the old mAbs against the 14 common serotypes (top half) that have been used previously (Lin et al., 2006). Two mAbs were chosen for the 11A serotype following our discovery of the two subtypes of 11A, which are described below. Hyp11AM2 is paired to bind to the 11A $\alpha$-PS-coated beads included in bead set 2 (11A PS from the ATCC is labelled as $11 \mathrm{~A} \alpha$ PS to avoid confusion). Hyp11AM1 is paired with the $11 \mathrm{~A} \beta$-PS-coated latex beads included in bead set 1 .

Cross-reaction patterns of the new mAbs suggest the existence of epitopes that have not yet been identified for pneumococcal PSs. The only epitope known to be expressed on serotypes 39 and 10A is epitope '10d' (Henrichsen, 1995). However, ' $10 \mathrm{~d}$ ' is known to be expressed on $10 \mathrm{~B}$, and Hyp10AM6 did not cross-react with 10B. Thus Hyp10AM6 may recognize a new epitope shared between only $10 \mathrm{~A}$ and 39 . In addition to this new epitope, we previously noted that Hyp18CM1 and Hyp23FG3 probably define new epitopes (Yu et al., 2005) since 18C- and 23F-specific epitopes were not described in the past (Henrichsen, 1995). Furthermore, we have recently described a new serotype, $6 \mathrm{C}$, the discovery of which revealed the presence of several new serogroup 6 epitopes (Park et al., 2007).

In previous multibead assays, latex beads had a short shelflife since PS was passively adsorbed to the beads. To prepare beads with a longer shelf-life, we covalently conjugated PS to the latex beads. Because one single method (the DMTMM method described above) of conjugating PS did not yield acceptable beads for all 25 different PSs, we examined two additional methods of conjugation (the EDC and PLL methods, also described above). Using these methods, we were able to produce PS-conjugated beads that were stable for more than 3 months. In many cases, the beads remained useful for more than 9 months. The sensitivity of the multibead assay was first investigated using purified PSs as inhibitors. Binding of all mAbs could be inhibited by more than $50 \%$ with $0.1 \mu \mathrm{g}$ homologous PS $\mathrm{ml}^{-1}$. This sensitivity was sufficient to allow the use of bacterial lysates diluted 10and 50-fold for multibead assays.

While we were investigating the conjugation methods, we found that the optimal conjugation method was dependent on the $\mathrm{mAb}$ itself. For instance, the PLL conjugation method yielded higher binding signals than the EDC conjugation method for mAb Hyp9VM5. However, the EDC method was better than the PLL method for mAb Hyp9VG1 (Fig. 1). Analogous differences were observed for $\mathrm{mAbs}$ to $22 \mathrm{~F}$ (Fig. 1). While these findings indicate that specific conjugation methods should be selected for each $\mathrm{mAb}$, they also suggest that one conjugation method could preserve a specific epitope better than another conjugation method. PS-conjugated latex beads are increasingly used for measuring concentrations of pneumococcal antibodies to many different serotypes using a flow-cytometer-like instrument (e.g. Luminex) (Pickering et al., 2002). In view of our findings, before adopting a flow-cytometric bead array method for measuring pneumococcal antibody levels, one should carefully investigate the potential that the epitopes can be altered by the method used to conjugate PS to latex beads (Pickering et al., 2002).

Next, the assay specificity was investigated using a panel of 147 pneumococcal isolates. The panel included 91 pneumococcal isolates representing all 91 currently known serotypes (Park et al., 2007). All mAbs reacted with the homologous serotype, but several mAbs cross-reacted with other serotypes (Table 1). For instance, the $\mathrm{mAb}$ Hyp10AM6 was reactive with serotype 10A and was also fully cross-reactive with serotype 39. Hyp7FM1 was fully reactive with serotype $7 \mathrm{~F}$ as well as with serotype $7 \mathrm{~A}$, as we previously reported (Yu et al., 2005). The presence of crossreactions was unambiguous because reactive samples always inhibited more than $67 \%$ and non-reactive samples always inhibited less than $33 \%$. Consequently, the crossreactions did not hinder serotype determinations.

The only exception to these unambiguous determinations was Hyp15BG5. With this mAb, all 15B isolates in the test panel inhibited more than $67 \%$ and could be identified unambiguously, but its cross-reaction with $15 \mathrm{C}$ isolates was highly variable. For instance, many $15 \mathrm{C}$ isolates inhibited about $40-60 \%$, but some $15 \mathrm{C}$ isolates inhibited less than $30 \%$. When Hyp15BG5 was examined with the purified PSs, Hyp15BG5 could be inhibited only by 15B PS and not by 15C PS (data not shown). The contradiction in cross-reactions observed with 15C PS and pneumococcal isolates can be explained since pneumococci expressing $15 \mathrm{C}$ can spontaneously convert to the $15 \mathrm{~B}$ serotype with an estimated frequency of approximately 1 in 250 bacteria (Venkateswaran et al., 1983) due to a genetically unstable acetylation enzyme gene in the cps locus (van Selm et al., 2003). Thus identification of $15 \mathrm{C}$ isolates with Hyp15BG5 is not based on a serological cross-reaction to 15C PS but is instead based on the spontaneous but variable conversion of $15 \mathrm{C}$ isolates to $15 \mathrm{~B}$ isolates.

\section{Use of bacterial lysates for PCR to identify additional serotypes}

The multibead assay is limited by the number of available mAbs. Also, the multibead assay did not reliably identify 

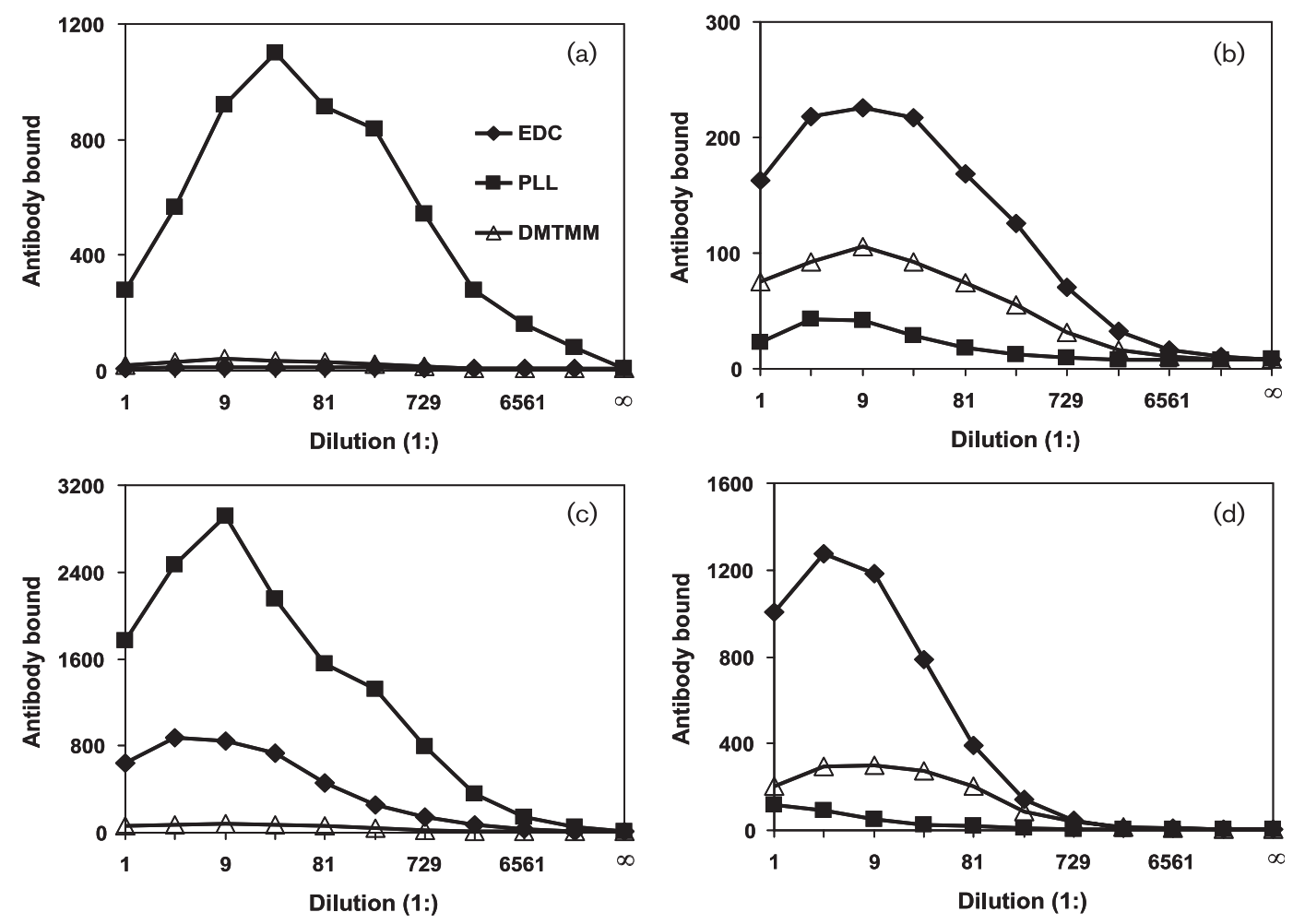

Fig. 1. Amount of $m A b$ bound to latex beads ( $y$-axis, in fluorescence units) at various dilutions of the mAb ( $x$-axis). (a) Binding of Hyp22FM1 or (b) Hyp22FM3 to latex beads conjugated to 22F PS using the EDC method (solid diamond), the PLL method (solid square) or the DMTMM method (open triangle). (c) Binding of Hyp9VM5 or (d) Hyp9VG1 to latex beads conjugated to 9V PS using the EDC method (solid diamond), the PLL method (solid square) or the DMTMM method (open triangle). 22Fconjugated beads prepared with the PLL method bind to Hyp22FM1 very well (a) but not to Hyp22FM3 (b). Also, 9Vconjugated beads prepared with the EDC method bind to Hyp9VG1 very well (c) but not to Hyp9VM5 (d). These four mAbs were not chosen for our serotyping assay.

serotype $15 \mathrm{C}$ due to variability in the observed crossreactions. To supplement the multibead assay, we studied the usefulness of the bacterial lysates originally prepared for the multibead assays in a multiplexed PCR. We chose to adopt the PCR method for the five serotypes 15A, 15C, $16 \mathrm{~F}, 35 \mathrm{~B}$ and 38 because a recent CDC survey showed that these five serotypes are more common among the serotypes not covered by the multibead assay (data not shown). As shown in Fig. 2, the lysates were useful for the multiplexed PCR (Pai et al., 2006) even with 100-fold dilutions. Serotype $15 \mathrm{C}$ could be identified with a PCR test for $15 \mathrm{~B}$ and 15C serotypes (Fig. 2) and its weak reaction with Hyp15BG5.

Also, we could use the lysates for PCRs for different targets, including additional pneumococcal serotype identification sequences ( 8 and 17F/A), the pneumolysin gene and multilocus sequence typing targets (data not shown) (Enright \& Spratt, 1998). In addition, we found that lysates prepared more than a year ago and kept frozen were useful for PCRs (data not shown). Thus the combination of serological and DNA testing makes the new assay system useful for epidemiological studies as well as for many reference laboratories due to its increased capacity to distinguish many more, if not all 91, serotypes.

\section{Validation of serotypic specificity of the new multibead assay with clinical isolates}

To use clinical isolates to validate our multibead assay, we obtained a panel of 157 clinical isolates from the CDC, where they had all been typed by the quellung reaction. The panel was constructed to preferentially include the serotypes that are detected with the new mAbs, and included more than 10 isolates for each serotype in the multibead assay except for serotype 2 . The isolates were analysed using the multibead assay. When the results were compared with the results of the CDC's quellung reaction tests, all the results were identical except for four discrepancies (Table 2). Three discrepancies were observed for serotype $11 \mathrm{~A}$, and one discrepancy was found for a strain (sample 3069-06) that was 'non-typable' at the CDC (Table 2) but was found to be weakly positive for serotype 8 at the University of Alabama at Birmingham (UAB). The non-typable strain (3069-06) was further investigated by 


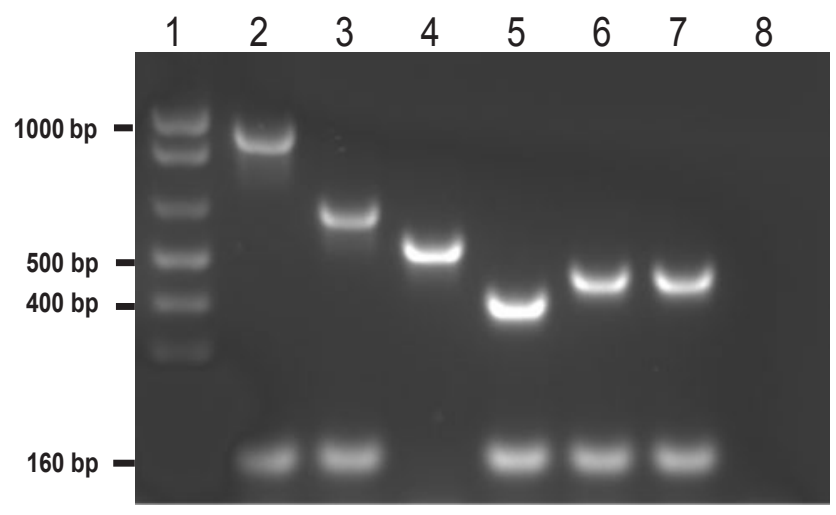

Fig. 2. Electrophoresis pattern of the products of a multiplexed PCR (for serotypes 15A, 15B, 15C, 16F, 35B and 38) using pneumococcal lysates expressing serotype $16 \mathrm{~F}$ (lane 2), serotype 35B (lane 3), serotype 38 (lane 4), serotype 15A (lane 5), serotype 15B (lane 6) and serotype 15C (lane 7). These strains were obtained from the Statens Serum Institut. Lane 8 has water as a negative control, and lane 1 shows the molecular ladder. Lysates were diluted 100-fold. Serotype-specific bands were found at the expected locations ( 988 bp for 16F, 677 bp for 35B, 574 bp for serotype 38, 436 bp for serotype $15 A$ and 496 bp for serotype $15 \mathrm{~B}$ or $15 \mathrm{C}$ ). The bands at $160 \mathrm{bp}$ are the PCR product of the cpsA gene, which is present in the capsule gene loci of almost all pneumococcal isolates (Bentley et al., 2006) and serves as a positive control for the presence of the pneumococcal capsule gene locus. This band is not detectable in some serotype 38 isolates (unpublished information from M. da G. S. Carvalho) (Bentley et al., 2006).

deriving 20 isolated subcolonies from the parental stock. Fourteen of the subcolonies were non-typable, but six colonies expressed serotype 8 .

Pneumococci expressing serotype 8 can spontaneously inactivate their initial transferase gene (cap $8 E)$ and lose capsule production by duplicating a large portion of the cap8E gene (Waite et al., 2003). This mechanism may have been responsible for some of the subcolonies of sample 3069-06 being typed as serotype 8 and others being nontypable. Therefore, we investigated both types of colonies for the size of the cap8E gene using PCR. Our study found that colonies expressing serotype 8 had a normal-sized cap $8 E$ gene but that the non-typable colonies did not have a cap8E gene even though they had the pneumococcal $\operatorname{cps} A$ gene (data not shown). Thus this sample harbours two pneumococcal strains: one expressing a non-typable serotype and the other expressing serotype 8 .

When the three discrepant $11 \mathrm{~A}$ isolates were further investigated, they were repeatedly typed as non-typable at UAB (with Hyp11AM2) but were retyped as $11 \mathrm{~A}$ by the quellung reaction. To investigate discrepancies in $11 \mathrm{~A}$ serotyping, we labelled the $11 \mathrm{~A}$ isolates reacting with Hyp11AM2 as $11 \mathrm{~A} \alpha$ and the three non-reactive isolates as $11 \mathrm{~A} \beta$. When we examined the panel of mAbs that we had prepared against $11 \mathrm{~A}$, we found that one $\mathrm{mAb}$ (Hyp11AM1) bound to the three $11 \mathrm{~A} \beta$ isolates better than to the $11 \mathrm{~A} \alpha$ isolates. The three $11 \mathrm{~A} \beta$ isolates inhibited the binding of Hyp 11AM1 to $11 \mathrm{~A} \beta$-coated latex beads but did not inhibit the binding of any other mAbs. Also, no isolates expressing the non-11A serotype could inhibit the binding of Hyp11AM1 to $11 \mathrm{~A} \beta$-coated latex beads. Thus the multibead assay system based on $26 \mathrm{mAbs}$ could correctly serotype all clinical isolates and also suggested the presence of subtypes among serotype 11A.

\section{Discovery of subtypes among 11A isolates}

To quantitatively study the $11 \mathrm{~A}$ subtypes, we developed an 11A-subtype-specific inhibition ELISA using the two mAbs (Hyp11AM1 and Hyp11AM2) and two subtypes of 11A PS. The 11A PS from the ATCC was inhibitory in the $11 \mathrm{~A} \alpha$ assay but not in the $11 \mathrm{~A} \beta$ assay (data not shown). Conversely, $11 \mathrm{~A} \beta$ PS inhibited the $11 \mathrm{~A} \beta$ assay but not the $11 \mathrm{~A} \alpha$ assay (data not shown). Consistent with multibead assay results, lysates of the $11 \mathrm{D}$ and $11 \mathrm{~F}$ serotypes inhibited the $11 \mathrm{~A} \alpha$ assay, but lysates of $11 \mathrm{~B}$ and $11 \mathrm{C}$ did not (data not shown). None of these lysates inhibited the $11 \mathrm{~A} \beta$ assay (data not shown). When we examined all 12 CDC samples that were identified as $11 \mathrm{~A}$ by the quellung reaction, six isolates inhibited the $11 \mathrm{~A} \alpha$ assay but not the $11 \mathrm{~A} \beta$ assay and three isolates inhibited the $11 \mathrm{~A} \beta$ assay but not the $11 \mathrm{~A} \alpha$ assay (Fig. 3). Interestingly, three isolates could inhibit both the $11 \mathrm{~A} \alpha$ assay and the $11 \mathrm{~A} \beta$ assay; an example is shown in Fig. 3. These results suggest the presence of serological subtypes in serotype 11A. However, we will not propose these subtypes to be new serotypes until the biochemical and genetic bases for the subtypes of $11 \mathrm{~A}$ are determined.

The potential discovery of serological subtypes within serotype $11 \mathrm{~A}$ is interesting since this serotype has been extensively investigated. Identification of these new subtypes in the wake of discovering serotype 6C within the well-established serotype 6A (Park et al., 2007) strongly suggests that the quellung reaction based on polyclonal antibodies may provide only limited serological specificity. We anticipate that additional subtypes will be discovered within other established serotypes and potentially among certain non-typable strains.

\section{Operational experience with the hybrid serotyping assay using both multibead and PCR assays}

We describe a hybrid serotyping system using both PCR and serological methods that shares the same sample (bacterial lysate). Since its development, our hybrid serotyping assay has already been used for typing more than 1000 samples. The multibead assay is well suited for primary screening since it has high throughput with reproducible results. Once one has appropriate instruments, the multibead assay costs less than PCR since it uses readily available latex particles, uses very small amounts of 
11Aa assay with Hyp11AM2

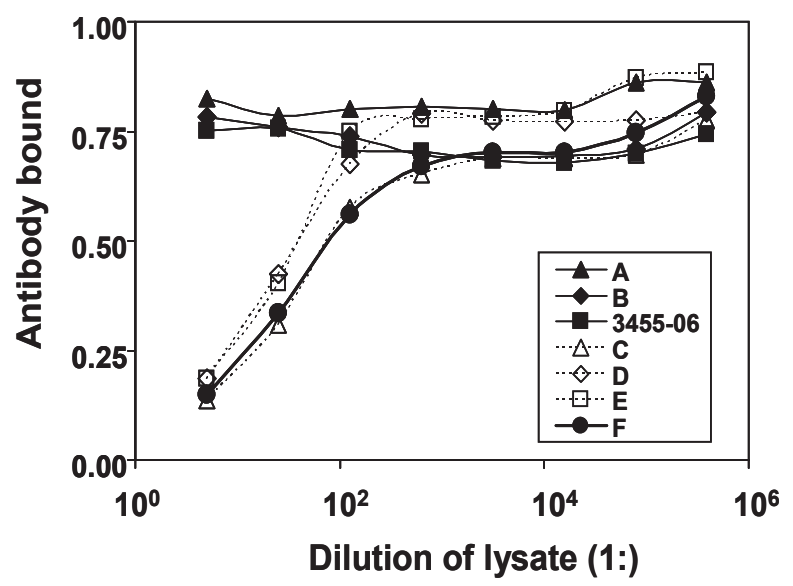

$11 \mathrm{~A} \beta$ assay with Hyp11AM1

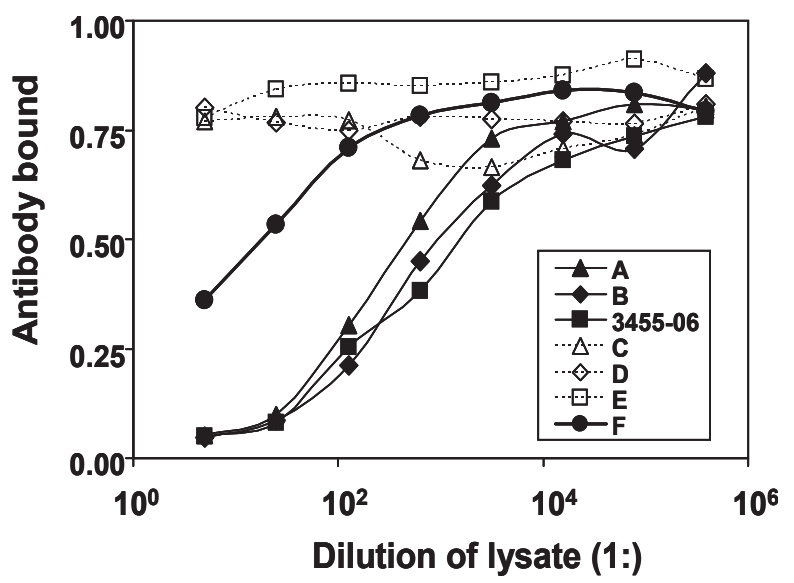

Fig. 3. Inhibition ELISA for distinguishing the $11 \mathrm{~A}$ subtypes. The left panel shows the binding of Hyp $11 \mathrm{AM} 2$ to $11 \mathrm{~A} \alpha \mathrm{PS}(y$-axis in absorbance units) in the presence of various dilutions of pneumococcal lysates ( $x$-axis in absorbance units). The right panel shows the binding of Hyp11AM1 to 11A $\beta$ PS ( $y$-axis) in the presence of various dilutions of pneumococcal lysates ( $x$-axis). Pneumococcal isolates $\mathrm{A}$ (solid triangle, solid line), $\mathrm{B}$ (solid diamond, solid line) and 3455-06 (solid square, solid line) are 11 A $\beta$ strains, and isolates $\mathrm{C}$ (open triangle, dotted line), D (open diamond, dotted line), E (open square, dotted line) and $\mathrm{F}$ (solid circle, solid line) are $11 \mathrm{~A} \alpha$ strains. Note that isolate $\mathrm{F}$ inhibits both $\mathrm{mAbs}$.

antibodies, and is highly automated. Indeed, the multibead assay alone is sufficient to determine the efficacy of current pneumococcal vaccines. Although we could serotype the majority of pneumococcal isolates with the multibead assay, the PCR method is a powerful complement in that it is readily adaptable to identify serotypes for which we currently have no serological reagents. This adaptability is useful when the prevalent serotypes are changing as a result of pneumococcal conjugate vaccine usage. We believe that this hybrid system, which shares one common bacterial lysate, has the capability to be highly precise, efficient and useful for laboratories with high-throughput serotyping needs.

\section{ACKNOWLEDGEMENTS}

The work was supported by NIH grant AI-30021 to M. H. N. Some hybridomas have been licensed to commercial entities.

\section{REFERENCES}

Ashwell, G. (1957). Colorimetric analysis of sugars. Methods Enzymol 3, 73-105.

Batt, S. L., Charalambous, B. M., McHugh, T. D., Martin, S. \& Gillespie, S. H. (2005). Novel PCR-restriction fragment length polymorphism method for determining serotypes or serogroups of Streptococcus pneumoniae isolates. J Clin Microbiol 43, 2656-2661.

Bentley, S. D., Aanensen, D. M., Mavroidi, A., Saunders, D., Rabbinowitsch, E., Collins, M., Donohoe, K., Harris, D., Murphy, L. \& other authors (2006). Genetic analysis of the capsular biosynthetic locus from all 90 pneumococcal serotypes. PLoS Genet 2, e31.
Brito, D. A., Ramirez, M. \& de Lencastre, H. (2003). Serotyping Streptococcus pneumoniae by multiplex PCR. J Clin Microbiol 41, 2378-2384.

Enright, M. C. \& Spratt, B. G. (1998). A multilocus sequence typing scheme for Streptococcus pneumoniae: identification of clones associated with serious invasive disease. Microbiology 144, 3049-3060.

Fenoll, A., Jado, A., Vicioso, D. \& Casal, J. (1997). Dot blot assay for the serotyping of pneumococci. J Clin Microbiol 35, 764-766.

Henrichsen, J. (1995). Six newly recognized types of Streptococcus pneumoniae. J Clin Microbiol 33, 2759-2762.

Kong, F., Wang, W., Tao, J., Wang, L., Wang, Q., Sabananthan, A. \& Gilbert, G. L. (2005). A molecular-capsular-type prediction system for 90 Streptococcus pneumoniae serotypes using partial cpsA-cpsB sequencing and wzy- or wzX-specific PCR. J Med Microbiol 54, 351-356.

Lawrence, E. R., Griffiths, D. B., Martin, S. A., George, R. C. \& Hall, L. M. (2003). Evaluation of semiautomated multiplex PCR assay for determination of Streptococcus pneumoniae serotypes and serogroups. J Clin Microbiol 41, 601-607.

Lin, J., Kaltoft, M. S., Brandao, A. P., Echaniz-Aviles, G., Brandileone, M. C., Hollingshead, S. K., Benjamin, W. H., Jr \& Nahm, M. H. (2006). Validation of a multiplex pneumococcal serotyping assay with clinical samples. J Clin Microbiol 44, 383-388.

Lund, E. (1960). Laboratory diagnosis of Pneumococcus infections. Bull World Health Organ 23, 5-13.

O'Halloran, D. M. \& Cafferkey, M. T. (2005). Multiplex PCR for identification of seven Streptococcus pneumoniae serotypes targeted by a 7-valent conjugate vaccine. J Clin Microbiol 43, 3487-3490.

Pai, R., Gertz, R. E. \& Beall, B. (2006). Sequential multiplex PCR approach for determining capsular serotypes of Streptococcus pneumoniae isolates. J Clin Microbiol 44, 124-131.

Park, M. K., Briles, D. E. \& Nahm, M. H. (2000). A latex bead-based flow cytometric immunoassay capable of simultaneous typing of multiple pneumococcal serotypes (Multibead assay). Clin Diagn Lab Immunol 7, 486-489. 
Park, I. H., Pritchard, D. G., Cartee, R., Brandao, A., Brandileone, M. C. \& Nahm, M. H. (2007). Discovery of a new capsular serotype (6C) within serogroup 6 of Streptococcus pneumoniae. J Clin Microbiol 45, $1225-1233$.

Pickering, J. W., Martins, T. B., Greer, R. W., Schroder, M. C., Astill, M. E., Litwin, C. M., Hildreth, S. W. \& Hill, H. R. (2002). A multiplexed fluorescent microsphere immunoassay for antibodies to pneumococcal capsular polysaccharides. Am J Clin Pathol 117, 589-596.

Rubin, L. G. \& Rizvi, A. (2004). PCR-based assays for detection of Streptococcus pneumoniae serotypes $3,14,19 \mathrm{~F}$ and $23 \mathrm{~F}$ in respiratory specimens. J Med Microbiol 53, 595-602.

Schlottmann, S. A., Jain, N., Chirmule, N. \& Esser, M. T. (2006). A novel chemistry for conjugating pneumococcal polysaccharides to Luminex microspheres. J Immunol Methods 309, 75-85.

Slotved, H. C., Kaltoft, M., Skovsted, I. C., Kerrn, M. B. \& Espersen, F. (2004). Simple, rapid latex agglutination test for serotyping of pneumococci (pneumotest-latex). J Clin Microbiol 42, 2518-2522.

van Selm, S., van Cann, L. M., Kolkman, M. A., van der Zeijst, B. A. \& van Putten, J. P. (2003). Genetic basis for the structural difference between Streptococcus pneumoniae serotype 15B and 15C capsular polysaccharides. Infect Immun 71, 6192-6198.
Venkateswaran, P. S., Stanton, N. \& Austrian, R. (1983). Type variation of strains of Streptococcus pneumoniae in capsular serogroup 15. J Infect Dis 147, 1041-1054.

Waite, R. D., Penfold, D. W., Struthers, J. K. \& Dowson, C. G. (2003). Spontaneous sequence duplications within capsule genes cap $8 E$ and tts control phase variation in Streptococcus pneumoniae serotypes 8 and 37. Microbiology 149, 497-504.

Whitney, C. G., Farley, M. M., Hadler, J., Harrison, L. H., Bennett, N. M., Lynfield, R., Reingold, A., Cieslak, P. R., Pilishvili, T. \& other authors (2003). Decline in invasive pneumococcal disease after the introduction of protein-polysaccharide conjugate vaccine. N Engl J Med 348, 1737-1746.

Wuorimaa, T. \& Kayhty, H. (2002). Current state of pneumococcal vaccines. Scand J Immunol 56, 111-129.

Yu, J., Lin, J., Benjamin, W. H., Jr, Waites, K. B., Lee, C. H. \& Nahm, M. H. (2005). Rapid multiplex assay for serotyping pneumococci with monoclonal and polyclonal antibodies. J Clin Microbiol 43, 156-162.

Zielen, S., Broker, M., Strnad, N., Schwenen, L., Schon, P., Gottwald, G. \& Hofmann, D. (1996). Simple determination of polysaccharide specific antibodies by means of chemically modified ELISA plates. J Immunol Methods 193, 1-7. 